\title{
Factors Responsible for Diabetes Among Adult People of Bangladesh
}

\author{
Keshab C Bhuyan ${ }^{1 *}$ and Jannatul Fardus ${ }^{2}$ \\ ${ }^{1}$ Jahangirnagar University, Bangladesh \\ ${ }^{2}$ American International University, Bangladesh \\ *Corresponding author: Keshab C Bhuyan, Jahangirnagar University, Savar, Dhaka, Bangladesh. \\ To Cite This Article: Keshab C Bhuyan. Factors Responsible for Diabetes Among Adult People of Bangladesh. Am J Biomed Sci \& Res. 2019 - 2(4). \\ AJBSR.MS.ID.000593. DOI: 10.34297/AJBSR.2019.02.000593
}

Received: March 18, 2019 | Published: April 17, 2019

\begin{abstract}
The present analysis was conducted in the American International University of Bangladesh using the data collected from 900 respondents. Among the respondents 70.6 percent were diabetic patients. Finding reveals that the largest percentage of patients was of the age group more than or equal to 50 years. About 34 percent patients were suffering from Type II diabetes and among them 63.3 percent were in the age group 50+ years. Higher prevalence rates of diabetes were observed among farmers and retired persons and among obese and severe obese group of persons. The factors responsible for diabetes were identified by logistic regression analysis using prevalence and non-prevalence of diabetes as dependent variable. Age was the most important influencing factor for diabetes followed by level of education of the respondents.
\end{abstract}

Keywords: Diabetic patients; Body Mass Index; Socio-demographic factors; Logistic Regression

\section{Introduction}

Diabetes is a disease characterized by excessive urination which is caused by insufficient insulin production or lack of responsiveness to insulin. The impact of insufficient insulin production is hyperglycemia. Thus, diabetes mellitus is a major and growing health problem in most countries and an important cause of prolonged disease and early death since insulin is essential to process carbohydrate, fat and protein [1]. Insufficient insulin production is associated with health problem such as gangrene, blindness, kidney failure, health failure, prolonged ill health and death due to vascular diseases [2-5]. The risk factors for cardiovascular disease are glucose and lipid abnormalities and the prevalence of this disease is a major factor due to diabetes in both developed and developing countries [6].

Nearly $80 \%$ of people with diabetes live in low- and middle-income countries [4]. Diabetes is prevalent among $10 \%$ people of Bangladesh and according to the international Diabetes Federation, the prevalence will be $13 \%$ by 2030 [4]. However, no nationally representative, epidemiological study of the prevalence of diabetes and its risk factors has been carried out in the country. People are also not aware, especially the rural people, of the disease and the factors responsible for the disease. There are mainly two types of diabetes, Type I and Type II. Type I diabetes may be caused by an autoimmune response and it is insulin dependent diabetes. Insulin is produced in the pancreas by the beta cells of the islets of Langer hans. Absence or destruction or loss of these cells causes an absolute deficiency of insulin leading to Type I diabetes. Type II diabetes is a heterogeneous disorder and the patients of this type of diabetes have insulin resistances their beta cells lack the ability to overcome this resistance. Whatever be the type of the disease, complications arise due to the disease. There are 3 major categories of complications and these are (a) acute, complications, (b) long-term complications, and (c) complications caused by associated autoimmune diseases. Acute compilations include hypoglycemia, hyperglycemia, and death during diagnosis. People, even the government, are not aware of the complication and as a result, the factors responsible for the disease are not well identified. The aim of this paper was to identify the socio-demographic variables responsible for diabetes among some people of rural and urban areas of Bangladesh. The important factors responsible for diabetes can be identified by doing logistic regression analysis.

\section{Methodology}

The analytical results were presented from the data collected from a sample of 900 persons living in Bangladesh. Among the respondents, prevalence of diabetes was observed among 635 persons and 235 persons were not affected by diabetes. The data were collected by postgraduate students of first and second -semester of 2014-2015 of American International University-Bangladesh. This group of students was doctors/nurses working in different 
hospitals / clinics. Some of them were involved in health services in both urban and rural areas. They had collected information from the working places/neighbors according to their convenience through pre-designed and pre-tested questionnaires. Five hundred forty-four people were interviewed by this group of students. Another 200 students of different disciplines were randomly selected from the university and they were asked to collect information from their parents/guardians. This latter group of students had collected information from 400 persons. But 44 filled-in questionnaires were found incomplete and these were discarded from the analysis. Finally, the analysis was done using the data of 900 persons.

The questionnaire contains questions related to socio-demographic characteristics of each person. Questionnaire also contains questions related to the stage of disease, treatment stage of disease, pre-caution against the disease and the stage of complications of the disease. The information regarding blood sugar level and blood pressure level were also collected according to the latest measureResults ment by doctors/diagnostic centers. The body mass index [ BMI, Weight in $\mathrm{kg}$ / (height in $\mathrm{cm} 2$ )] for every respondent was calculated. The respondents were classified as underweight (if BMI < 20), overweight (if BMI was 20-25), obese (if BMI was 25-30) and severe obese (if BMI was 30+) [7]. Data were classified for diabetic and non-diabetic people and accordingly association of diabetes and socio-demographic variables of respondents were studied. Significant association was determined by chi-square test with $\mathrm{p}$-value $<0.05$. The statistical analysis is done by using the SPSS [version 17.0; 8] and MATLAB.

The logistic regression analysis $[9,10]$ was done using the variables residence, age, sex, education, occupation, type of work, and income, body mass index as explanatory variables and prevalence of diabetes [ yes $=1, \mathrm{no}=0$ ] as dependent variable. Here sex, occupation, residence, and type of work were nominal variables. Thus, we have transferred all the variables in nominal form by assigning numbers.

\begin{tabular}{|c|c|c|c|c|c|c|}
\hline \multirow{3}{*}{$\begin{array}{l}\text { Prevalence of } \\
\text { Diabetes }\end{array}$} & \multicolumn{4}{|c|}{ Residential Origin } & \multicolumn{2}{|c|}{ Total } \\
\hline & \multicolumn{2}{|c|}{ Rural } & \multicolumn{2}{|c|}{ Urban } & \multirow{2}{*}{$\mathrm{n}$} & \multirow{2}{*}{$\%$} \\
\hline & $\mathrm{n}$ & $\%$ & $\mathrm{n}$ & $\%$ & & \\
\hline Yes & 138 & 21.7 & 497 & 78.3 & 635 & 70.6 \\
\hline No & 29 & 10.7 & 236 & 89.3 & 265 & 29.4 \\
\hline Total & 167 & 18.6 & 733 & 81.4 & 900 & 100 \\
\hline
\end{tabular}

Among 900 respondents sampled 635 were diabetic patients (70.6\%). Since objective of the study was not to find an estimate of prevalence rate, the investigated variables were classified by prevalence of diabetes and by other socioeconomic characteristics. The classified results were shown in tabular form and the classified results were used to test the independence of any two characters (Table 1).

As shown in Table 1, the prevalence of diabetes was observed among $78.3 \%$ urban people and $21.7 \%$ among rural people. Prev- alence of diabetes according to residential origin was significantly higher in urban area recorded from the uni-variate analysis ( $p$-value $<0.001$ ). This finding was similar with the finding observed at national level [11], where more urban people were diabetic patients $(67.8 \%)$ compared to non-diabetic patients. Among the respondents $58.9 \%$ were males and $71.1 \%$ of them were diabetic. Among females $69.7 \%$ were diabetic patients. The differentials in prevalence of diabetes according to sex were not statistically significant $(p$ - value $=0.65$, Table 2 ).

\begin{tabular}{|c|c|c|c|c|c|c|}
\hline \multirow{3}{*}{$\begin{array}{c}\text { Prevalence of } \\
\text { diabetes }\end{array}$} & \multicolumn{4}{|c|}{ Sex } & \multicolumn{2}{|c|}{ Total } \\
\hline & \multicolumn{2}{|c|}{ Male } & \multicolumn{2}{|c|}{ Female } & \multirow{2}{*}{$\mathrm{n}$} & \multirow{2}{*}{$\%$} \\
\hline & $\mathrm{n}$ & $\%$ & $\mathrm{n}$ & $\%$ & & \\
\hline Yes & 377 & 71.1 & 258 & 69.7 & 635 & 70.6 \\
\hline No & 153 & 28.9 & 112 & 30.3 & 265 & 29.4 \\
\hline Total & 530 & 58.9 & 370 & 41.1 & 900 & 100 \\
\hline
\end{tabular}

\begin{tabular}{|c|c|c|c|c|c|c|c|c|c|c|}
\hline \multirow{3}{*}{$\begin{array}{c}\text { Prevalence } \\
\text { of } \\
\text { diabetes }\end{array}$} & \multicolumn{8}{|c|}{ Age groups (in years) } & \multicolumn{2}{|c|}{ Total } \\
\hline & \multicolumn{2}{|c|}{$<25$} & \multicolumn{2}{|c|}{$25-40$} & \multicolumn{2}{|c|}{$40-50$} & \multicolumn{2}{|c|}{ over $50+$} & \multirow[t]{2}{*}{$\mathrm{n}$} & \multirow[t]{2}{*}{$\%$} \\
\hline & $\mathrm{n}$ & $\%$ & $\mathrm{n}$ & $\%$ & $\mathrm{n}$ & $\%$ & $\mathrm{n}$ & $\%$ & & \\
\hline Yes & 7 & 36.8 & 62 & 50 & 180 & 64.1 & 386 & 81.1 & 635 & 70.6 \\
\hline No & 12 & 63.2 & 62 & 50 & 101 & 35.9 & 90 & 18.9 & 265 & 29.4 \\
\hline Total & 19 & 2.1 & 124 & 13.8 & 281 & 31.2 & 476 & 52.9 & 900 & 100 \\
\hline
\end{tabular}

In different studies [11,12-14] it was reported that prevalence of diabetes was higher among the middle aged and among older people. In this study also it was seen that among $52.9 \%$ of respondents in the age group $50+$ years $81.1 \%$ were diabetic (Table 3). 
The prevalence rate was significantly lower among the lower aged group of respondents $(p<0.001)$. This finding is consistent with that observed globally.

Out of 900 respondents 635 were diabetics (70.6\%) and among them 50.1 percent were in the obese and severe obese group (Table 4) against the overall percentage (49.3\%) of these groups of respondents. All most 50 percent respondents were in obese and severe obese groups and these levels of obesity were mostly responsible for higher prevalence rate of diabetes. The study indicated that increase in level of obesity was significantly associated with the prevalence of diabetes $[\mathrm{p}$-value $<0.000$ ]. Similar findings were observed in both home and abroad [15-17]. It has been reported $[12,16]$ that positive association exists between diabetes and level of education. It has also been reported [1] that there is significant association between level of education and pre-diabetes. In the present study also, significant association was observed between prevalence of diabetes and level of education (p-value 0.001). More than $62 \%$ of (Table 5) respondents were at least graduated and among them $64.8 \%$ were affected by diabetes. The results indicated that there was negative association between prevalence of diabetes and level of education. Similar findings are also observed in some developed and developing countries [12,16] (Table 5).

\begin{tabular}{|c|c|c|c|c|c|c|c|c|c|c|}
\hline \multirow{3}{*}{$\begin{array}{c}\text { Prevalence } \\
\text { of } \\
\text { diabetes }\end{array}$} & \multicolumn{8}{|c|}{ Level of obesity } & \multirow{3}{*}{$\begin{array}{c}\text { Total } \\
n\end{array}$} & \multirow{3}{*}{$\%$} \\
\hline & \multicolumn{2}{|c|}{ Underweight } & \multicolumn{2}{|c|}{ Over weight } & \multicolumn{2}{|c|}{ Obese } & \multicolumn{2}{|c|}{ Severe Obesity } & & \\
\hline & $\mathrm{n}$ & $\%$ & $\mathrm{n}$ & $\%$ & $\mathrm{n}$ & $\%$ & $\mathrm{n}$ & $\%$ & & \\
\hline Yes & 46 & 67.6 & 271 & 69.8 & 217 & 70.9 & 101 & 73.2 & 635 & 70.6 \\
\hline No & 22 & 32.4 & 117 & 30.2 & 89 & 29.1 & 37 & 26.8 & 265 & 29.4 \\
\hline Total & 68 & 7.4 & 388 & 43.3 & 306 & 34.5 & 138 & 14.8 & 900 & 100 \\
\hline
\end{tabular}

\begin{tabular}{|c|c|c|c|c|c|c|c|c|c|c|c|c|}
\hline \multirow{3}{*}{$\begin{array}{l}\text { Prevalence of } \\
\text { diabetes }\end{array}$} & \multicolumn{10}{|c|}{ Level of education } & \multicolumn{2}{|c|}{ Total } \\
\hline & \multicolumn{2}{|c|}{ Illiterate } & \multicolumn{2}{|c|}{ Primary } & \multicolumn{2}{|c|}{ Secondary } & \multicolumn{2}{|c|}{ Graduate } & \multicolumn{2}{|c|}{ Post Graduate } & \multirow{2}{*}{$\mathrm{n}$} & \multirow{2}{*}{$\%$} \\
\hline & $\mathrm{n}$ & $\%$ & $\mathrm{n}$ & $\%$ & $\mathrm{n}$ & $\%$ & $\mathrm{n}$ & $\%$ & $\mathrm{n}$ & $\%$ & & \\
\hline Yes & 30 & 83.3 & 73 & 88 & 167 & 76.6 & 240 & 66.3 & 125 & 62.2 & 635 & 70.6 \\
\hline No & 6 & 16.7 & 10 & 12 & 51 & 23.4 & 122 & 33.7 & 76 & 37.8 & 265 & 29.4 \\
\hline Total & 36 & 4 & 83 & 9.2 & 218 & 24.2 & 362 & 40.2 & 201 & 22.4 & 900 & 100 \\
\hline
\end{tabular}

There were $4.3 \%$ agriculturists in the sample and prevalence rate of diabetes among them were higher (87.2\% Table 6). Largest prevalence rate was observed among employees of private organizations. The second higher prevalence rate was observed among retired persons. The higher prevalence rate among these two groups of people may be due to non-involvement with physical labors/ activities. In the sample, a good number of people (18.9\%) were not involved with any physical labor. This proportion among diabetes patients was 0.268 (Table 7). The prevalence rate was expected to be higher among them. The differentials in prevalence rate according to respondent's occupation were statistically significant as p-value 0.01 (Table 6).

Table 6: Distribution of respondents according to occupation and prevalence of diabetes.

\begin{tabular}{|c|c|c|c|c|c|c|c|c|c|c|c|c|c|c|}
\hline \multirow{3}{*}{$\begin{array}{c}\text { Prevalence } \\
\text { of } \\
\text { diabetes }\end{array}$} & \multicolumn{13}{|c|}{ Occupation } & \multirow{3}{*}{$\begin{array}{c}\text { Total } \\
\%\end{array}$} \\
\hline & \multicolumn{2}{|c|}{ Agriculture } & \multicolumn{2}{|c|}{ Business } & \multicolumn{2}{|c|}{ Govt. Service } & \multicolumn{2}{|c|}{ Private Service } & \multicolumn{2}{|c|}{ Retired } & \multicolumn{2}{|c|}{ Housewife } & \multirow{2}{*}{$\mathrm{n}$} & \\
\hline & $\mathrm{n}$ & $\%$ & $\mathrm{n}$ & $\%$ & $\mathrm{n}$ & $\%$ & $\mathrm{n}$ & $\%$ & $\mathrm{n}$ & $\%$ & $\mathrm{n}$ & $\%$ & & \\
\hline Yes & 34 & 87.2 & 151 & 72.2 & 101 & 65.6 & 130 & 62.8 & 85 & 76.6 & 134 & 74.4 & 635 & 70.6 \\
\hline No & 5 & 12.8 & 58 & 27.8 & 53 & 34.4 & 77 & 37.2 & 26 & 23.4 & 46 & 25.6 & 265 & 29.4 \\
\hline Total & 39 & 4.3 & 209 & 23.2 & 154 & 17.1 & 207 & 23 & 111 & 12.3 & 180 & 20 & 900 & 100 \\
\hline
\end{tabular}

\begin{tabular}{|c|c|c|c|c|c|c|c|c|c|c|}
\hline \multirow{3}{*}{$\begin{array}{l}\text { Types of } \\
\text { Diabetes }\end{array}$} & \multicolumn{8}{|c|}{ Age group (in years) } & \multicolumn{2}{|c|}{ Total } \\
\hline & \multicolumn{2}{|c|}{$<25$} & \multicolumn{2}{|c|}{$25-40$} & \multicolumn{2}{|c|}{$40-50$} & \multicolumn{2}{|c|}{$50+$} & \multirow{2}{*}{$\mathrm{n}$} & \multirow{2}{*}{$\%$} \\
\hline & $\mathrm{n}$ & $\%$ & $\mathrm{n}$ & $\%$ & $\mathrm{n}$ & $\%$ & $\mathrm{n}$ & $\%$ & & \\
\hline I & 3 & 2.3 & 20 & 15.8 & 46 & 34.8 & 63 & 47.7 & 132 & 20.8 \\
\hline II & 3 & 1.4 & 25 & 11.6 & 51 & 23.7 & 136 & 63.3 & 215 & 33.8 \\
\hline III & 0 & 0 & 2 & 10.5 & 3 & 15.8 & 14 & 73.7 & 19 & 3 \\
\hline Unknown & 1 & 0.4 & 15 & 5.6 & 80 & 29.7 & 173 & 64.3 & 269 & 42.4 \\
\hline Total & 7 & 1.1 & 62 & 9.8 & 180 & 28.3 & 386 & 60.8 & 635 & 100 \\
\hline
\end{tabular}


It has already been mentioned that $70.6 \%$ respondents were diabetic patients. These respondents were classified by their type of diabetes and according to their age (Table 7) and type of work they do (Table 8). A good number (269 out of 635) of patients were unaware about their type of diabetes (Table 7).

Only $20.8 \%$ were suffering from Type I diabetes and $47.7 \%$ of them were in the age group over 50 years old. This differential by age and type of diabetes was significant as ( $p$ 0.01). The study indi- cated that most of the patients were suffering from Type II diabetes. This result is similar to that observed in a separate study [1].

Higher proportion of diabetic patients was doing physical labor and $27.5 \%$ of them were suffering from Type II diabetes. The corresponding figure among the patients who were not doing work with physical labor is 40.6. There were significant differences in the proportions of respondents suffering from diabetes according to the type of work they do (p 0.01) (Table 8).

\begin{tabular}{|c|c|c|c|c|c|c|c|c|c|c|}
\hline \multirow{3}{*}{ Types of Diabetes } & \multicolumn{8}{|c|}{ Type of works } & \multicolumn{2}{|c|}{ Total } \\
\hline & \multicolumn{2}{|c|}{ Only official work } & \multicolumn{2}{|c|}{$\begin{array}{l}\text { Office work with physical } \\
\text { labor }\end{array}$} & \multicolumn{2}{|c|}{ Physical labor } & \multicolumn{2}{|c|}{$\begin{array}{l}\text { Work without physical } \\
\text { labor }\end{array}$} & \multirow[t]{2}{*}{$\mathrm{n}$} & \multirow[t]{2}{*}{$\%$} \\
\hline & $\mathrm{n}$ & $\%$ & $\mathrm{n}$ & $\%$ & $\mathrm{n}$ & $\%$ & $\mathrm{n}$ & $\%$ & & \\
\hline I & 40 & 24.7 & 22 & 16.7 & 33 & 19.3 & 37 & 21.8 & 132 & 20.8 \\
\hline II & 63 & 38.9 & 36 & 27.3 & 47 & 27.5 & 69 & 40.6 & 215 & 33.8 \\
\hline III & 5 & 3.1 & 4 & 3 & 4 & 2.3 & 6 & 3.5 & 19 & 3 \\
\hline Unknown & 54 & 33.3 & 70 & 53 & 87 & 50.9 & 58 & 34.1 & 269 & 42.4 \\
\hline Total & 162 & 25.5 & 132 & 20.8 & 170 & 26.9 & 170 & 26.8 & 635 & 100 \\
\hline
\end{tabular}

\section{Results of Logistic Regression}

It was observed that prevalence of diabetes was associated with some of the socio-demographic variables of the respondents. The prevalence was measured by yes $=1$ and no $=0$ and we had a binary variable. This binary variable was used as dependent variable to fit a binary logistic model. The explanatory variables were used residence, age, education, occupation, gender, marital status, religion, type of work, income, smoking habit and body mass index.
The regression results showed that main cause of diabetes was the age followed by level of education. Though the impacts of residence, gender, income, smoking habit and level of BMI were not statistically significant, it revealed that urban people were 1.474 times exposed to diabetes. Lower educated people also were 1.309 times more exposed to diabetes. Females, smokers, rich people were also more exposed to diabetes. The overall regression results were significant [Wald Statistic $=142.79$, p-value $=0.000$; Nagelkerke R2 = 0.135] (Table 9).

\begin{tabular}{|c|c|c|c|c|}
\hline Variable & Coefficient, B & Wald Statistic & $\mathrm{p}$-value & $\operatorname{Exp}(B)$ \\
\hline Residence & 0.388 & 2.481 & 0.115 & 10474 \\
\hline Age & -0.028 & 44.163 & 0 & 0.972 \\
\hline Gender & 0.242 & 1.403 & 0.236 & 1.274 \\
\hline Education & 0.27 & 7.67 & 0.006 & 1.309 \\
\hline Occupation & -0.055 & 0.83 & 0.362 & 0.946 \\
\hline Work type & 0.053 & 1.036 & 0.309 & 1.055 \\
\hline Income & 0.008 & 0.01 & 0.92 & 1.008 \\
\hline Marital status & -0.032 & 0.019 & 890 & 0.969 \\
\hline Religion & -0.039 & 0.033 & 0.855 & 0.961 \\
\hline Smoking habit & 0.078 & 0.156 & 0.693 & 1.081 \\
\hline BMI & -0.021 & 1.663 & 0.197 & 0.98 \\
\hline Constant & -1.229 & 2.172 & 0.141 & 0.29 \\
\hline
\end{tabular}

\section{Discussion and Conclusion}

Higher prevalence rate of diabetes was observed among male respondents. Higher educated people were less affected by diabetes. Prevalence rates of diabetes were higher among illiterate, primary educated and secondary level educated people. The prevalence rates of diabetes were higher among farmers and retired persons and the prevalence rate was lower among the lower aged respondents. Among the respondents $26.8 \%$ are not doing any physical labor and $40.6 \%$ of them are suffering from Type II diabe- tes. This percentage is obviously higher compared to the percentages of other groups of respondents. Among the diabetic patients $60.8 \%$ were in the age group over 50 years and above. This result is similar to that observed in a different work [1]. Analytical results indicated that among the diabetic patients most of them were from urban area. This result is similar as is observed in another study $[7,9]$.

This is probably due to the fact that we were mainly interested to study the factors important for diabetes and accordingly mostly 
diabetic patients were investigated. Age was significantly associated with diabetes. The logistic regression analysis also indicated that the age was an influencing factor to enhance the prevalence of diabetes among the people. These findings are similar as are observed around the world [11]. Two studies conducted in China and India confirmed this finding $[16,18]$. The analysis indicated that prevalence of diabetes was significantly different according to different socio-demographic variables. The variable age was the main factor for increasing the prevalence rate of diabetes followed by education. Education was significantly positively associated with prevalence of diabetes. It indicated that higher educated people were more aware about the health hazard of diabetes. The inverse association between diabetes and education are also observed in both developing and developed countries [21,22].

Occupation and income were important components of socioeconomic status of people. In this study both the variables were found significantly associated with diabetes. Higher prevalence rate was observed among retired persons and among persons involved in work without physical labor. In some studies, socioeconomic status and diabetes are inversely associated. The risk of diabetes is increased with the increase of socioeconomic status [15-21,22-23]. Our findings are similar with the findings mentioned above. Most of the findings reported here are consistent with the findings by other research workers in Bangladesh, India and Pakistan [16,17,22,23]. Some of the social factors associated with the prevalence of diabetes are identified by Chi-square test as is usual process used in other studies in Bangladesh, China and India $[16,17,22]$. In this paper to identify the most important social factors responsible for diabetes logistic regression analysis was done. The analysis identified some of the risk factors for prevalence of diabetes and these factors were age, education, work type and residence. The prevalence rate of diabetes was more among the aged and retired persons.

Diabetes is a serious problem of health hazard in Bangladesh. However the challenge of this health problem can be tackled by (a) incorporating some techniques to investigate the people occasionally to check the health condition of them and accordingly they can be advised to take care of health, (b) encouraging all adults and retired persons participate at blood screening program so that they can be alerted against the health hazard of diabetes, (c) encouraging the people, especially among urban area to do some sorts of physical activities. The public health authority can play a decisive role for the above steps.

\section{References}

1. Rahaman M, Islam J (2007) Problems with diabetes and awareness to its control: Experienced from Diabetes Patients of Rajshahi City Corporation in Bangladesh.

2. (2003) International Diabetic Federation (IDF). Diabetes atlas ( $\left.2^{\text {nd }} E d n\right)$. The International Diabetes Federation, Brussels, Belgium, Europe.

3. Lozano R, Naghvi M, Foreman K, Lim S, Shibuya K, et al. (2012) Global and regional mortality from 235 causes of death for 20 age groups in 1990 and 2010: a systematic analysis for the global Burden of disease study 2010. Lancet 380(9859): 2095-2128.

4. Murray CJL, Vos T, Lozano R, Naghavi M, Flaxman AD, et al. (2012) Disability-adjusted life years for 291 disease and injuries in 21 regions,
1990-2010, a systematic analysis for the Global Burden of disease study 2010. Lancet 380(9859): 2197-2223.

5. Arunachalam S, Gunasekaran S (2002) Diabetes research in India and China today; From literature-based mapping to health-care policy. Current Science 82(9): 1086-1087.

6. Prakash Chandra RD, Naidoo DP (2016) Glycaemic control profile in diabetic patients: A sub-analysis of the phoenix lifestyle project. Euromediterranean Biomedical Journal 11(5): 33-39.

7. Jannatul F, Bhuyan KC (2016) Discriminaing diabetic patients of some rural and urban area of Bangladesh: A discriminant Analysis Approach. Euromeditererranean Biomedical Journal for young doctors 11(19): 134-140.

8. Norusis MJ (1990) SPSS/PC+ Advanced Statistics TM 4.01 BM PC/XT AT and PS/2, Illinois.

9. Bhuyan KC, Rahaman S, Jannat F (2017) Body mass index and diabetes associated with socioeconomic factors among adult people of Bangladesh. AJSE 16(1.2.3): 187-192.

10. Urmi AF, Bhuyan KC (2018) Obesity in children and adolescents and the factors responsible for it: A case study among children of some affluent families. Int Diab Card Dis 3(1): 56-66.

11. Akter S, Rahman MM, Abe SK, Sultana P (2014) Prevalence of diabetes and prediabetes and their risk factors among Bangladeshi adults: a nationwide survey. Bulletin of the World Health Organization 92(3): 204-213A.

12. International Diabetes Federation (IDF). Diabetes atlas, $\left(6^{\text {th }}\right.$ Edn) (Internet). Country estimates table 2011. The International Diabetes Federation 2012.

13. Rahim MA, Hussain A, Azad Khan, Sayeed MA, Keramat Ali SM, et al. (2007) Rising Prevalence of Type II Diabetes in rural Bangladesh: A Population based study. Diabetes Res Clin Pract 77(2): 300-305.

14. Calamusa G, Amodio E, Costantino C. et al. (2012) Body mass index and factors associated with overweight and obesity: A cross-sectional study of adult subjects living in a small city of Western Sicily (Italy). Italian Journal of Public Health 9(3): e7539.

15. Mokdad AH, Ford ES, Bowman BA, Dietz WH, Vinicor F, et al. (2003) Prevalence of obesity, diabetes, and obesity related health risk factors 2001. The Journal of American Medical Association 289(1): 76-79.

16. Yang W Lu, Weng J, Jia W, Ji L, Xiao J, et al. (2010) China National Diabetes and Metabolic Disorders Study Group, et al. Prevalence of diabetes among men and women in China. N Engl J med 362: 1090-1101.

17. Ramchandra A, Sneha Lata C, Kapur A, Vijay V, Mohan V, et al. (2001) Diabetes Epidemiology Study Group in India (DESL) et al. High prevalence of diabetes and impaired glucose tolerance in India: National Urban Diabetes Survey. Diabetologia 44(9): 1094-1101.

18. Duc Son LN, Kusama K, Hung NT, Loan TT, Chuyen NV, et al. (2004) Prevalence and risk factors for diabetes in Ho Chi Minh City, Vietnam. Diabet Med 21: 371-376.

19. Borrell LN, Dallo FJ, White K (2006) Education and diabetes in a racially and ethnically Diverse population. Am J Public Health 96(9): 1637-1642.

20. Ahsan HN, Islam MZ, Alam MB, et al. (2011) Prevalence and risk factors of Type 2 diabetes mellitus among Secretariat employees of Bangladesh. J Med 12: 125-130.

21. Bhowmik B, Afsana F, My Diep L, Binte Munir S, Wright E, et al. (2013) Increasing prevalence of Type 2 diabetes in a rural Bangladeshi population: a population-based study for 10 years. Diabetes Metlab J 37(1): 46-53.

22. Abu Sayeed M, Ali L, Hussain MZ, Rumi MA, Banu A, et al. (1997) Effect of Socioeconomic risk factors on the difference in prevalence of diabetes between rural and urban population in Bangladesh, Diabetes Care 20(4): 551-555 
23. Shera AS, Rafique G, Khawaja IA, Baqai, King H. et al. (1999) Pakistan National Diabetes Survey: Prevalence of glucose intolerance and associated factors in Baluchistan province. Diabetes Res Clin Pract 44(1): 49-58. 